\title{
Identificação de tipos de papilomavirus e de outros fatores de risco para neoplasia intra-epitelial cervical
}

Identification of papillomavirus types and other risk factors for cervical intraepithelial neoplasia

Terezinha Tenório da Silva ${ }^{1}$, Mariléa de Lima Guimarães ${ }^{2}$, Maria Isabel de Castro Barbosa ${ }^{2}$, Maria de Fátima Garpar Pinheiro ${ }^{2}$, Angelina Farias Maia ${ }^{2}$

\section{RESUMO}

\begin{abstract}
Objetivo: identificar os fatores de risco para neoplasia intra-epitelial cervical (NIC) e os tipos de papilomavírus humano (HPV) em mulheres com NIC, e comparar com os tipos de HPV entre as que apresentam colo normal. Métodos: foram estudadas 228 pacientes, sendo 132 portadoras de NIC (casos) e 96 mulheres com colo normal (controles). Nos dois grupos, formados por pacientes selecionadas entre aquelas que procuraram atendimento no mesmo hospital e residiam em área próxima ao local da

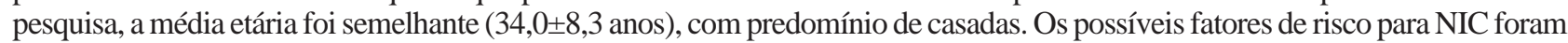
investigados com aplicação de questionário, pesquisando: idade, estado civil, grau de escolaridade, idade do primeiro coito, número de gestações, número de parceiros sexuais, método contraceptivo utilizado, referência de doenças sexualmente transmissíveis (DST) anteriores e tabagismo, comparados entre os grupos estudados. Foram coletadas amostras para colpocitologia oncótica e, a seguir, para pesquisa de HPV por reação em cadeia de polimerase (PCR), utilizando iniciadores (primers) MY09 e MY11, procedendo-se então ao exame colposcópico e exame histopatológico. Para análise estatística de associação de NIC com fatores de risco, utilizaram-se odds ratio com intervalo de confiança e os testes $\chi^{2}$ e Fisher, ao nível de significância de 0,05 . Empregou-se ainda o método de regressão logística testado com significância expressa pelo valor de p com grau de máxima verossimilhança. Resultados: no modelo de regressão logística permaneceram as variáveis: infecção por HPV de alto risco oncogênico (OR=12,32; IC 95\%: 3,79-40,08), referência à DST anterior (OR=8,23; IC 95\%: 2,82-24,04), idade precoce do primeiro coito $(\mathrm{OR}=4,00$; IC 95\%: 1,70-9,39) e tabagismo (OR=3,94; IC 95\%: 1,73-8,98). APCR foi positiva em 48,5\% e 14,6\% nos grupos caso e controle, respectivamente. Conclusões: o fator de risco principal para NIC foi infecção por HPV oncogênico, com os tipos 16, 18, $33,35,51,52,58$ e 83. Dentre as portadoras de lesões de alto grau, houve predomínio de HPV-16 ou variante 16 . Nas pacientes com colo morfologicamente normal, também foram identificados os tipos oncogênicos 51, 58 e variante 51.
\end{abstract}

PALAVRAS-CHAVE: Neoplasia intra-epitelial; Doenças sexualmente transmissíveis; Reação em cadeia de polimerase; Tabagismo; Fatores de risco

\section{ABSTRACT}

Purpose: to identify risk factors for cervical intraepithelial neoplasia (CIN) and human papillomavirus (HPV) types among women with CIN, and to compare with HPV types among patients with normal cervix. Methods: a total of 228 patients were studied, of whom 132 with CIN (cases) and 96 with normal cervix (controls). In the two groups consisting of women selected among outpatients attended in the same hospital, living near the place of the research, mean ages were similar (34.0 \pm 8.3 years) and there was a predominance of married women. Possible risk factors for CIN were investigated with the application of a questionnaire surveying age, marital status, level of schooling, age at first coitus, number of pregnancies, number of sexual partners, method of used contraception, reference of previously sexually transmitted diseases (STDs) and smoking habits, with a comparison between the studied groups. Samples were collected for oncologic colpocytology and HPV search through polymerase chain reaction (PCR), using MY09/MY11 primers; then colposcopic and histopathological examinations were performed. For statistical analysis of the association between risk factors and CIN, odds ratio with $95 \%$ confidence interval and $\chi^{2}$ and Fisher tests were used at a significance level of 0.05 . The logistic regression method with the significance expressed by the p value with maximum likelihood was also applied. Results: the following variables remained

Serviço de Ginecologia do Hospital das Clínicas da Universidade Federal de Pernambuco - UFPE - Recife (PE), Brasil.

1 Professora Adjunto. Doutora em Ginecologia da Universidade Federal de Pernambuco - UFPE - Recife (PE), Brasil.

2 Médicas Colpocitologistas do Hospital das Clínicas da Universidade Federal de Pernambuco - UFPE - Recife (PE), Brasil.

Correspondência: Terezinha Tenório

Rua Nossa Senhora do Loreto, 238 - Piedade - 54420-200 - Jaboatão dos Guararapes - PE - Fone: (81) 33611274 - Fax: (81) 21268513 - e-mail: teresinhatenorio@uol.com.br 
in the logistic regression model: HPV infection of high oncogenic risk ( $O R=12.32$; CI 95\%: 3.79-40.08), reference of previous STDs (OR=8.23; CI 95\%: 2.82-24.04), early age at first coitus (OR=4.00; CI 95\%: 1.70-9.39) and smoking habit (OR=3.94; CI 95\%: 1.73-8.98). PCR was positive in 48.5 and $14.6 \%$ in the case and control groups, respectively. Conclusions: the main risk factor for CIN was oncogenic HPV infection, with types $16,18,33,35,51,52,58$, and 83. Among patients with a high-degree lesion, there was a predominance of HPV-16 or type 16 variant. In patients with normal cervix oncogenic, HPV types 51, 58, and 51 variant were also identified.

KEYWORDS: Cervical intra-epithelial neoplasia; Sexually transmitted diseases; Polymerase chain reaction; Smoking; Risk factors

\section{Introdução}

Entre os fatores de risco para o surgimento do câncer cervical uterino e de suas lesões precursoras, a infecção cervical por tipos oncogênicos do papilomavírus humano (HPV) tem sido estabelecida dentro dos critérios de causalidade. Certos tipos de HPV são admitidos como fator causal necessário, porém não suficiente, na etiopatogenia da lesão neoplásica ${ }^{1}$. O desenvolvimento do câncer cervical é menos provável na ausência da infecção pelo HPV e de fatores coexistentes, que favorecem a persistência da infecção, entre os quais: tabagismo, uso de contraceptivos orais, antecedente de múltiplos parceiros sexuais, multiparidade, início precoce das relações sexuais e déficit nutricional e imunológico, além de fatores genéticos ${ }^{1,2}$.

Utilizando técnicas de biologia molecular, demonstrou-se que a associação entre infecção pelo HPV e desenvolvimento de neoplasia intraepitelial cervical NIC é forte, com risco relativo variando entre 20 e $70^{1}$. É consistente com resultados reproduzidos em diferentes populações; é temporalmente plausivel, uma vez que estudos de coorte demonstram inquestionavelmente que a infecção precede o início das lesões intraepiteliais, além de ser biologicamente plausivel e coerente, contribuindo para o melhor conhecimento a respeito da história natural da doença ${ }^{1}$.

Os tipos de HPV são classificados como de baixo risco, entre os quais: $6,11,42,44,70$ e 73 , e de alto risco oncogênico, associados com lesões intra-epiteliais e câncer, como os tipos 16, 18, 31, $33,34,35,39,45,51,52,56,58,59,66$ e 68 . A classificação taxonômica baseia-se na seqüência de nucleotídeos dos HPV, claramente correlacionada com seu tropismo tissular e seu potencial oncogênico. Além destes, existe um grupo intermediário de HPV, 26, 54 e 70, para os quais ainda não existe base epidemiológica que defina seu potencial oncogênico ${ }^{1,3}$. Essa correlação entre tipos de HPV de alto risco, câncer cervical e suas lesões precursoras ficou mais evidente após os estudos nos quais se identificou DNA de HPV de alto risco em 84 a 99,7\% dos cânceres cervicais ${ }^{2,4}$.
O objetivo principal desta pesquisa foi identificar os fatores de risco para NIC, incluindo a infecção por HPV, em estudo comparativo com mulheres sem lesão cervical. A identificação dos fatores de risco para NIC em região com elevada incidência de câncer cervical invasivo, como o local onde o estudo foi realizado, contribui para a implementação de estratégias de prevenção e diagnóstico precoce.

\section{Métodos}

Realizou-se estudo do tipo caso-controle, no qual foram incluídas 132 portadoras de NIC em seus diferentes graus (casos) e 96 pacientes sem lesão cervical (controles).

Como critérios de inclusão no estudo, foram admitidas as mulheres que já tiveram ou que têm atividade sexual e procuraram atendimento espontâneo, seja como prevenção rotineira do câncer ginecológico ou porque foram encaminhadas para comprovação diagnóstica no Setor de Colposcopia do Hospital das Clínicas da Universidade Federal de Pernambuco, durante o período de novembro de 2001 a agosto de 2002.

Os critérios de exclusão da pesquisa foram: gravidez, histerectomia e ser portadora de déficit mental que prejudicasse o entendimento e as respostas para o preenchimento do formulário específico.

Optou-se por maior número de casos por limitações econômicas, uma vez que, além dos métodos morfológicos, rotineiros em nosso serviço, foi utilizado também a reação em cadeia de polimerase (PCR), que é método dispendioso. Como os resultados desse tipo de estudo são expressos pela razão dos produtos cruzados odds ratio (OR), tal medida não é influenciada pela relação do número de casos e de controles ${ }^{5}$.

Todas as pacientes assinaram o termo de consentimento livre e esclarecido, previamente aprovado junto com o projeto de pesquisa pelo Comitê de Ética em Pesquisas da Universidade Federal de Pernambuco. A abordagem das pacientes, para esclarecimento e obtenção da concordância em participar da pesquisa, foi realizada pela autora do 
trabalho, que também obteve respostas às perguntas contidas no formulário pré-codificado. Foram admitidas como caso as portadoras de NIC em seus diferentes graus, diagnosticadas por atipias colposcópicas, colpocitológicas e histopatológicas. Foram admitidas como controles as pacientes que residiam na vizinhança dos casos, buscavam atendimento no mesmo hospital e apresentaram o exame colposcópico e a colpocitologia oncótica com resultados normais, em três ocasiões sucessivas com intervalo de dois anos, assim como por ocasião do estudo. Os dois grupos da amostra foram pareados, não se observando diferenças quanto às características epidemiológicas (Tabelas 1 e 2).

Tabela 1 - Características biossociais das mulheres com neoplasia intra-epitelial cervical em comparação ao grupo controle sem lesões.

\begin{tabular}{|c|c|c|c|c|c|}
\hline \multirow[t]{2}{*}{ Características amostrais } & \multicolumn{3}{|c|}{ Grupos } & \multirow[b]{2}{*}{ OR IC } & \multirow[b]{2}{*}{$p$} \\
\hline & & $\begin{array}{l}\text { aso } \\
\text { (\%) }\end{array}$ & $\begin{array}{c}\text { Controle } \\
n \quad(\%)\end{array}$ & & \\
\hline Grupo etário (anos) & & & & & 0,88 \\
\hline $10-29$ & 46 & $(34,8)$ & $33(34,4)$ & 1,00 & \\
\hline $30-39$ & 53 & $(40,2)$ & $34(35,4)$ & $1,12 \quad 0,60-2,08$ & 0,57 \\
\hline $40-59$ & 33 & $(25,0)$ & $29(30,2)$ & $0,820,42-1,60$ & 0,67 \\
\hline Estado civil & & & & & 0,84 \\
\hline Casada & 63 & $(47,7)$ & $46(47,9)$ & 1,00 & \\
\hline Solteira & 53 & $(40,2)$ & $36(37,5)$ & $1,070,61-1,90$ & 0,92 \\
\hline Viúva ou separada & 16 & $(12,1)$ & $14(14,6)$ & $0,830,37-1,88$ & 0,82 \\
\hline Grau de instrução & & & & & 0,02 \\
\hline Sem instrução ou elementar & 29 & $(22,0)$ & $9 \quad(9,4)$ & 1,00 & \\
\hline Fundamental a superior & 103 & $(78,0)$ & $87(90,6)$ & $0,370,17-0,82$ & \\
\hline Total & 132 & $(100,0)$ & $96(100,0)$ & & \\
\hline
\end{tabular}

$\mathrm{OR}=$ odds ratio; IC $95 \%$ = intervalo de confiança a $95 \%$.

Tabela 2 - Características reprodutivas das mulheres com neoplasia intra-epitelial cervical em comparação ao grupo controle sem lesões.

\begin{tabular}{|c|c|c|c|c|}
\hline \multirow{2}{*}{$\begin{array}{l}\text { Características } \\
\text { reprodutivas }\end{array}$} & \multicolumn{2}{|c|}{ Grupos } & \multirow[b]{2}{*}{ OR IC 95\% } & \multirow[b]{2}{*}{$p$} \\
\hline & $\begin{array}{l}\text { Caso } \\
\text { n (\%) }\end{array}$ & $\begin{array}{c}\text { Controle } \\
\text { n (\%) }\end{array}$ & & \\
\hline Idade ao primeiro coito & & & & 0,00 \\
\hline $20-30$ & $17(12,9)$ & $30(31,2)$ & 1,00 & \\
\hline $10-19$ & $115(87,1)$ & $66(68,8)$ & $3,071,58-5.00$ & \\
\hline Número de gestações & & & & 0,17 \\
\hline Nuligesta & $11(8,3)$ & $13(13.5)$ & 1,00 & \\
\hline Primigesta & $20(15,2)$ & $16(16,7)$ & $1,48 \quad 0,52-4,17$ & 0,64 \\
\hline Paucigesta & $49(37,1)$ & $42(43,8)$ & $1,38 \quad 0,56-3,40$ & 0,64 \\
\hline Multigesta & $52(39,4)$ & $25(26,0)$ & $2,460,97-6,26$ & 0,09 \\
\hline Número de parceiros sexuais & & & & 0,03 \\
\hline $1-2$ & $67(50,8)$ & $62(64,6)$ & 1,00 & \\
\hline 3 ou mais & $65(49,2)$ & $34(35,4)$ & $1,771,03-3,04$ & \\
\hline Referência de DST anterior & & & & 0,00 \\
\hline Não & $63(47,7)$ & $66(68,8)$ & 1,00 & \\
\hline Sim & $69(52,3)$ & $30(31,2)$ & $2,41 \quad 1,39-4,18$ & \\
\hline
\end{tabular}

OR = odds ratio; IC 95\% = intervalo de confiança a 95\%; DST = doença sexualmente transmissivel.
Tendo como base o estudo das variáveis: idade, estado civil, grau de instrução, idade ao primeiro coito, número de gestações, número de parceiros sexuais, método contraceptivo utilizado, antecedente de doença sexualmente transmissível (DST) e tabagismo, foram identificadas nas pesquisadas as características biossociais, reprodutivas e os fatores de risco para NIC. Foram consideradas como tabagistas ou fumantes as pacientes que referiam consumo superior a quatro cigarros por dia. A variável método contraceptivo utilizado foi definida como método utilizado para evitar a gravidez, nos três meses que antecederam a pesquisa, categorizada em: anticoncepcional oral ou injetável, condom, tabela, dispositivo intra-uterino e outros.

A seqüência de exame das pacientes foi: coleta de material para colpocitologia oncótica, coleta de material para identificação de HPV por PCR utilizando iniciadores (primers) MY09/MY11, colhido em tubos Eppendorf contendo meio de transporte. Em seguida, foi realizado o exame colposcópico e as imagens atípicas foram biopsiadas, permitindo o exame histopatológico.

Para descrição dos aspectos colposcópicos, seguiu-se a Classificação da Nomenclatura Internacional dos Aspectos Colposcópicos de Roma ${ }^{6}$. Utilizando-se aparelho marca INAMI $^{\circledR}$, as imagens colposcópicas foram analisadas após colocação de soro fisiológico $0,9 \%$ no colo e fórnices vaginais, após uso de solução de ácido acético 3\% e, por fim, utilizando-se Lugol para realização do teste de Schiller. Foram considerados atípicos os achados colposcópicos: epitélio acetobranco, plano e micropapilar, pontilhado, mosaico, leucoplasia, zona iodo negativa e vasos atípicos ${ }^{6}$. Essas imagens foram biopsiadas utilizando-se pinça de Gaylor-Medina,

Para diagnóstico de NIC, definida pela presença de desarranjo estrutural no epitélio estratificado no material de biópsia com ausência de invasão da membrana basal, foram utilizados os critérios descritos por Richart ${ }^{7}$, e para descrição dos esfregaços citológicos do colo uterino, os critérios baseados no Sistema Bethesda ${ }^{8}$.

Os iniciadores sintetizados pela Life Technologies $^{\mathrm{TM}}$ MY09 e MY11 foram utilizados na amplificação da região L1 do virus, para obtenção de um filamento completo de 450 pares de bases. Os oligonucleotídeos GH20 e PC04, que amplificam uma região de aproximadamente 268 pares de bases do gene $\beta$-globina humana, foram utilizados como controle interno. A eletroforese dos fragmentos de digestão por endonuclease de restrição produziu mapas genéticos característicos de cada um dos tipos virais estudados, os quais foram compa- 
rados com os mapas de restrição dos diferentes tipos de HPV já conhecidos ${ }^{3}$. As amostras que apresentaram padrão indeterminado foram submetidas ao seqüenciamento genético ${ }^{3}$, cujo método pode ser sumarizado nas seguintes etapas: fase de purificação do DNA genômico, amplificação para incorporação dos cromóforos, precipitação dos produtos de PCR e obtenção dos dados por meio de sistema computadorizado com aparelho MegaBace ${ }^{\circledR} 1000$, com visualização da eletroforese. Por meio de alinhamento das seqüências de nucleotídeos obtidos, realizou-se análise por similaridade BLAST, com seqüências similares, disponiveis no banco de dados genéticos $(\mathrm{NCBI})^{9}$.

Para análise estatística de associação de NIC com os fatores de risco, utilizaram-se o OR com intervalo de confiança (IC) e os testes $\chi^{2}$ e Fisher, ao nivel de significância de 0,05. Para ajuste do efeito de cada uma das variáveis pelas demais, empregou-se o modelo de regressão logística, testado com significância expressa pelo valor de p com grau de máxima verossimilhança.

\section{Resultados}

Dentre as características biossociais das pacientes nos grupos em estudo, observou-se variação etária de 18 a 50 anos, com média igual a $34,0 \pm 8,3$ anos. Houve maior número de mulheres casadas, em ambos os grupos. Quanto ao grau de instrução, 22\% dos casos e 9,4\% dos controles possuíam nenhuma instrução ou instrução elementar, sendo a diferença estatisticamente significante (v. Tabela 1). Quanto às características reprodutivas, constatou-se que as médias etárias da primeira relação sexual foram de $16,5 \pm 2,9$ anos e $18,2 \pm 3,8$ anos, para o grupo caso e o grupo controle, respectivamente.

A chance de desenvolver NIC foi três vezes mais elevada nas mulheres com idade ao primeiro coito entre 10 e 19 anos, quando comparado com o grupo que teve o primeiro coito entre 20 e 30 anos. Constatou-se ter havido de um a dois parceiros sexuais em 50,8 e 64,6\% das pacientes do grupo caso e controle, respectivamente, embora três ou mais parceiros sexuais tenha sido mais freqüente no grupo caso. A referência de doença sexualmente transmissivel anterior à pesquisa foi mais freqüente nas pacientes do grupo caso, sendo a chance de apresentar NIC aproximadamente duas vezes maior no grupo com antecedente de DST (v. Tabela 2).

Verificou-se que a maioria das mulheres não era tabagista, independentemente do grupo a que pertencia, no entanto as fumantes estiveram con- centradas no grupo caso. A chance de desenvolver NIC foi cinco vezes maior no grupo de fumantes, quando comparado ao de não fumantes (Tabela 3).

Tabela 3 - Distribuição de 132 portadoras de neoplasia intra-epitelial cervical e 96 controles conforme tempo de tabagismo e consumo diário de cigarros.

\begin{tabular}{|c|c|c|c|c|c|c|}
\hline \multirow{2}{*}{$\begin{array}{l}\text { Características do } \\
\text { tabagismo }\end{array}$} & \multicolumn{3}{|c|}{ Grupos } & \multirow[b]{2}{*}{ OR } & \multirow[b]{2}{*}{ IC 95\% } & \multirow[b]{2}{*}{$p$} \\
\hline & $\begin{array}{l}\text { Caso } \\
\text { n (\%) }\end{array}$ & $\underset{n}{\text { Con }}$ & $\begin{array}{c}\text { ntrole } \\
(\%)\end{array}$ & & & \\
\hline Tabagismo & & & & & & 0,00 \\
\hline Não & $73(55,3)$ & 83 & $(86,5)$ & 1,00 & & \\
\hline Sim & $59(44,7)$ & 13 & $(13,5)$ & 5,16 & $2,62-10-16$ & \\
\hline Tempo de tabagismo (anos) & & & & & & 0,75 \\
\hline $1-9$ & $18(30,5)$ & 4 & $(30,8)$ & 1,00 & & \\
\hline$\geq 10$ & $41(69,5)$ & 9 & $(69,2)$ & 1,01 & $0,28-3,72$ & \\
\hline Consumo diário de cigarros & & & & & & 0,95 \\
\hline $1-19$ & $26(44,1)$ & 5 & $(38,5)$ & 1,00 & & \\
\hline$\geq 20$ & $33(55,9)$ & 8 & $(61,5)$ & 0,79 & $0,23-2,71$ & \\
\hline
\end{tabular}

OR = odds ratio; IC 95\% = intervalo de confiança a $95 \%$.

$\mathrm{Na}$ análise multivariada, foram identificados como fatores de risco para NIC, em ordem decrescente de grandeza, risco oncogênico do HPV, referência de DST anterior, idade ao primeiro coito e tabagismo (Tabela 4). Considerada a distribuição amostral do presente estudo, a positividade para DNA-HPV igualou-se a $34,2 \%$, correspondentes a 78 amostras, nas quais identificaram-se diversos tipos de HPV. No grupo caso, em 64 das 132 pacientes houve positividade, e no grupo controle, em 14 das 96 pacientes, o que correspondeu a percentual igual a 48,5 e 14,6\%, respectivamente. No grupo caso, dentre os diversos tipos identificados, houve predominio do HPV-16 ou variante 16 (30/46,9\%). O HPV-16 foi tipo único em 18 amostras (60\%) e esteve associado a outros tipos em três (10\%); a variante do mesmo tipo viral foi identificada em nove (30\%) pacientes.

Tabela 4 - Odds ratios ajustados e intervalos de confiança (IC) da associação entre neoplasia intra-epitelial cervical e demais variáveis.

\begin{tabular}{lcc}
\hline Fatores de risco & Odds ratio ajustado & IC 95\% \\
\hline Risco oncogênico & 1,0 & \\
$\quad$ Não & 12,3 & $3,7-40,0$ \\
Sim & & \\
Referência de DST anterior & 1,0 & $2,8-24,0$ \\
$\quad$ Não & 8,2 & \\
Sim & & $1,7-9,3$ \\
Idade ao primeiro coito & 1,0 & \\
$20-30$ & 4,0 & $1,7-8,9$ \\
10-19 & & \\
Tabagismo & 1,0 & \\
Não & 3,9 & \\
Sim & & \\
\hline DST = doença sexualmente transmissível. &
\end{tabular}


Houve 15 casos $(23,4 \%)$ nos quais, apesar da positividade do DNA-HPV e da tentativa de seqüenciamento, o tipo viral não pôde ser determinado. No grupo controle, o HPV-16 e a variante 16 estiveram ausentes. Em nove amostras (64,3\%) quais não se pôde tipar o HPV. No entanto, dentre as amostras com HPV tipado, quatro $(28,6 \%)$ eram de alto risco oncogênico e uma $(7,1 \%)$, de baixo risco (Quadro 1).

Quadro 1 - Demonstrativo dos tipos de HPV encontrados e da pesquisa de HPV em casos indeterminados em mulheres com e sem neoplasia intra-epitelial cervical.

\begin{tabular}{|ll|}
\hline $\begin{array}{l}\text { Grupo } \\
\text { de estudo }\end{array}$ & \multicolumn{1}{c|}{ Tipagem de HPV } \\
\hline Casos & Tipos: 13, 16, 18, 33, 35, 44, 51, 52, 58, 67, 83 e \\
& CP141/LVX, além de variantes 16, 33, 44, 51, 58 e 83 \\
& HPV indeterminado: 15 amostras \\
Controles & Tipos: CP 141/LVX, 51, 58, além de variante 51 \\
& HPV indeterminado: 9 amostras \\
\hline HPV = papilomavírus humano.
\end{tabular}

Analisando a associação entre NIC e risco oncogênico do HPV, calculamos que a chance de mulheres com HPV de alto risco oncogênico desenvolverem NIC foi treze vezes maior no grupo caso que no controle $(\mathrm{OR}=13,26$; IC 95\%: 4,34-38,78; $\mathrm{p}<0,001)$. Considerando a presença de HPV-16 ou variante 16, para o grupo caso, identificou-se ter sido mais freqüente a presença desse tipo viral nas pacientes com NIC 2 ou NIC 3 que naquelas com lesão de baixo grau (dado não mostrado em tabela).

\section{Discussão}

Em Recife, capital de Pernambuco, local onde o estudo foi realizado, como acontece em várias regiões do Brasil, a cobertura dos serviços de prevenção da neoplasia cervical é deficitária. Em pesquisa anteriormente realizada na mesma cidade, dentre as mulheres atendidas em um setor de colpocitologia do Sistema Único de Saúde, 64,5\% dos exames colpocitológicos foram diagnosticados como processos inflamatórios e 5,4\% continham material inadequado, isto é, contribuindo para a má qualidade da análise oncológica ${ }^{10}$. A dificuldade de acesso aos serviços de prevenção do câncer do colo do útero pode ser agravada pelo deficiente grau de escolaridade nesta região, tal como constatado na presente pesquisa, na qual, no grupo caso, houve elevado contingente de pacientes sem instrução ou detentoras apenas de conhecimentos elementares.

O início precoce de relações sexuais mostrou-se, na presente pesquisa, como fator de risco para NIC, tal como em estudos de coorte já realizados ${ }^{11}$. Entre as jovens, há reconhecida vulnerabilidade biológica às infecções sexualmente transmissiveis, de modo geral ${ }^{11,12}$. A ectopia cervical, também freqüente nesta fase evolutiva, induz à metaplasia, como mecanismo natural de reparação, favorecendo a transmissão do HPV e de outros microrganismos ${ }^{11}$.

No presente estudo, multigestação não representou fator de risco para NIC, embora tenha ocorrido maior freqüência de multíparas entre os casos do que entre os controles. Por outro lado, o relato de três ou mais parceiros sexuais e a referência de DST anterior constituíram fator de risco para NIC, tal como referido na literatura ${ }^{11,12}$.

O uso de contraceptivo hormonal foi mais freqüente entre os casos, mas a diferença não foi significante. Alguns autores salientam que o uso de contraceptivos hormonais orais como fator de risco para NIC pode ser conseqüente a viés de seleção ou grupos de controle inapropriados. Dentre as usuárias de contraceptivos hormonais, as neoplasias cervicais podem apresentar maior freqüência, como resultado da melhor atenção à saúde da mulher e solicitação da colpocitologia oncótica ${ }^{1,13}$.

A associação entre tabagismo e NIC foi estatisticamente significante, resultado similar ao referido por outros autores ${ }^{1}$. Entre as fumantes, há significante decréscimo da densidade das células de Langerhans na zona de transformação do epitélio escamoso do colo do útero, sugerindo efeito supressivo na imunidade mediada por células ${ }^{14}$. Esses autores demonstraram que, entre as fumantes, 10,7 meses foi a média de duração da infecção cervical por HPV, comparada com a média de duração de 8,5 meses entre as não tabagistas, salientando que o hábito de fumar favorece a infecção persistente e, conseqüentemente, a carcinogênese ${ }^{14}$.

$\mathrm{O}$ elevado número de pacientes portadoras de NIC, nas quais não se identificou DNA-HPV pela técnica de PCR no estudo atual, assemelha-se aos resultados de outras pesquisas ${ }^{15}$. Para esses autores, a justificativa do encontro de $80 \%$ de portadoras de NIC 1 sem a presença de DNA-HPV, em estudo por eles realizado, parece adequada também para a elevada negatividade de DNA-HPV da presente pesquisa. Afirmam que "HPV negativo necessariamente não significa sempre negativo", justificando que em muitos casos a seqüência de DNA-HPV pode ser positiva, porém em quantidade de nucleotídeos tão pequena que os métodos atuais não permitem detectar ${ }^{15}$.

Assim como no presente estudo, o HPV-16 é o tipo prevalente em lesões neoplásicas cervicais em todo o mundo, com exceção da Indonésia, onde o HPV-18 é mais freqüentemente identificado ${ }^{2}$. Na 
América do Sul e na América Central, os tipos virais mais prevalentes são: $16,18,45,31$ e $33^{2}$. No Brasil, estudos anteriores de prevalência do HPV em lesões cervicais foram realizados em cinco regiões. Em todas elas, o HPV-16 é predominante em algumas cidades das regiões Norte, Nordeste, Sudeste e Sul, apesar de ter sido também observada variedade dos outros tipos virais ${ }^{16}$.

Em recente pesquisa realizada em Brasília, os autores identificaram DNA-HPV em 62\% das 129 portadoras de NIC, entre as quais: HPV-16 em 43,8\%, HPV-58 em 12,5\%, HPV-31 em 10\%, HPV53 em 6,3\% e HPV-18 e HPV-33, ambos em 3,8\% das pacientes ${ }^{17}$. Os autores chamam a atenção para a maior freqüência de HPV oncogênico entre as pacientes com lesões histopatológicas de alto grau, à semelhança dos resultados encontrados no estudo ora apresentado.

Considerando a freqüência geral de DNA-HPV em que a PCR foi positiva, encontraram-se $82,1 \%$ no grupo caso e 17,9\% no controle; pode-se admitir que a população estudada apresenta risco elevado para neoplasia cervical. O percentual de positividade nos casos é semelhante ao encontrado na literatura $62,78,5,82$, e $91,2 \% \%^{9,18-21}$. A diferente distribuição de tipos oncogênicos nas populações, tal como constata-se na literatura, tem importância na produção de vacinas adequadas a cada região, contendo os tipos virais mais prevalentes ${ }^{12}$.

Apesar do valor inquestionável e da alta sensibilidade da PCR para detecção do HPV, esta técnica pode ter resultados falso-negativos. A não identificação de HPV em todos os casos de NIC pode resultar de alguns fatores, entre os quais: problemas na coleta dos espécimes; dificuldade nos testes para HPV existentes, em decorrência da incompleta quantidade de vírus descobertos, e limitações dos testes atuais ${ }^{21}$.

Como ocorre com os métodos de biologia molecular, assim como em outras modalidades de diagnóstico complementar, os resultados estão condicionados à técnica empregada, no que tange à sensibilidade e especificidade. Dado que toda técnica preconizada para identificação do HPV por PCR foi seguida corretamente com iniciadores MY09/ MY11, a pequena quantidade de nucleotídeos contida nas amostras indeterminadas, assim como a freqüente negatividade de DNA-HPV em portadoras de NIC, contrariando a literatura, pode ter sido resultante do momento da coleta, ou seja, segundo a metodologia proposta no estudo, a seqüência de coleta de espécimes foi: em primeiro lugar, material para colpocitologia oncótica, utilizando-se espátula de Ayre e escova cytobrush, e, a seguir, coleta do material para pesquisar o HPV, utilizando-se escova cytobrush, após retirada do muco ectocervical com gaze. É possivel que a menor quantidade de células, agora coletada, e o freqüente processo inflamatório local possam ter contribuído para esse resultado. Mesmo confeccionadas com finas cerdas, as escovas utilizadas para coleta do material endocervical para colpocitologia produziam, com freqüência, discreto sangramento, principalmente quando havia inflamação cervicovaginal. O espécime sanguinolento contém hemoglobina suficiente para impedir o processo de amplificação molecular ${ }^{21}$. Mesmo no afã de identificar o vírus, não se poderia prejudicar a avaliação citomorfológica das pacientes, colhendo espécime para PCR em primeiro lugar e postergando a obtenção do espécime para estudo citológico, que resultaria no retardo do diagnóstico e do tratamento, com suas negativas conseqüências.

Dentre os fatores citados na carcinogênese cervical, destaca-se a infecção persistente por tipos oncogênicos de HPV ${ }^{1}$. A disponibilização dos testes para HPV, como método adjuvante à colpocitologia na prevenção das neoplasias cervicais, é um importante avanço, porém, até o momento, não há dados comprobatórios suficientes de que esta combinação promoverá melhores resultados, redução dos custos ou melhor aceitação pelas mulheres do que a colpocitologia isolada ${ }^{18}$. Além do mais, para os mesmos autores, metade dos casos de câncer cervical surge entre aquelas que não participam do rastreamento regular. Reconhecem ainda como elevadas a sensibilidade e a especificidade dos dois exames na detecção das lesões de alto grau, quando utilizados em conjunto, em mulheres com idade superior a $30 \operatorname{anos}^{18}$.

Apesar desses conhecimentos, observa-se maior solicitação dos testes de biologia molecular no processo de rastreamento das neoplasias cervicais e, em alguns casos, antecedendo o estudo citomorfológico, inclusive para mulheres jovens, nas quais a prevalência da infecção cervical pelo HPV é elevada e transiente. Ressalte-se que a prevalência do HPV é inversamente proporcional à idade, havendo regressão de NIC 2 e NIC 3 em 58 e 47\% dos casos, respectivamente, apenas após a biópsia ${ }^{19}$. Cerca de $15 \%$ das mulheres que se submetem rotineiramente aos testes preventivos e que possuem citologia negativa e DNA-HPV de alto risco terão citologia anormal em cinco $\operatorname{anos}^{22}$. Ressalte-se, no entanto, que a história natural do HPV rumo à carcinogênese cervical ainda não está totalmente esclarecida ${ }^{20}$. Admite-se que é influenciada por vários co-fatores, que interferem na regressão ou progressão das lesões HPV-induzidas, e que colposcopia, colpocitologia e histopatologia são os exames indicados para identificar as portadoras de atipias celulares ${ }^{23,24}$

Este estudo permitiu identificar grupos que têm maior probabilidade de desenvolver NIC, quais sejam, aquelas pacientes portadoras de HPV de alto risco, com antecedente de DST, que tiveram início precoce da relação sexual e as tabagistas. Para esses grupos de pacientes deve haver esforço maior dos progra- 
mas de prevenção, para identificá-los e, a seguir, garantir atendimento diferenciado com os métodos de diagnóstico e aconselhamento, objetivando evitar o surgimento ou a progressão dessas lesões.

\section{Agradecimento}

Os autores agradecem ao Prof. Dr. Eduardo Ramalho e a Profa. Dra. Denise Wanderlei, responsáveis pelo Serviço de Biologia Molecular da Universidade Federal de Alagoas, cujo trabalho foi fundamental na identificação do papilomavrus humano.

\section{Referências}

1. Franco EL, Duarte-Franco E, Ferenczy A. Cervical cancer: epidemiology, prevention and the role of human papillomavirus infection. CMAJ. 2001;164(7):1017-25.

2. Bosch FX, Manos MN, Muñoz N, Sherman M, Jansen AM, Peto J, et al. Prevalence of human papillomavirus in cervical cancer: a worldwide perspective. J Natl Cancer Inst. 1995;87(11):796-802.

3. Ting Y, Manos MM. Detection and typing of genital human papillomavirus. In: Innis A, Gelfand DH, Sninsky JJ, White TJ, editors. PCR protocols: a guide to methods and applications. New York: Academic Press; 1990. p. 356-67.

4. Walboomers JM, Jacobs MV, Manos MM, Bosch FX, Kummer JA, Shah KV, et al. Human papillomavirus is a necessary cause of invasive cervical cancer worldwide. J Pathol. 1999;189(1):12-9.

5. Schelesselman JJ. Case-control studies. Design, conduct, analysis. 3rd ed. New York: Oxford University Press; 1982.

6. Sociedade Brasileira de Patologia do Trato Genital Inferior e Colposcopia (SBPTGIC). Terminologia colposcópica. Bol Inf Dir SBPTGIC. 2003;(5):5-6.

7. Richart RM. A modified terminology for cervical intraepithelial neoplasia. Obstet Gynecol. 1990;75(1):131-3.

8. Berek JS. Simplification of the new Bethesda 2001 classification system. Am J Obstet Gynecol. 2003;188(3 Suppl):S2-5.

9. National Center for Biotechnology (NCBI). Nucleotide Sequence Update.[cited 2004 Sep 25] available from: http://www.ncbi.nlm.nih.gov

10. Lorenzato F, Ho L, Terry G, Singers A, Santos LC, De Lucena Batista R, et al. The use of human papillomavirus typing in detection of cervical neoplasia in Recife (Brazil). Int J Gynecol Cancer. 2000;10(2):143-50.

11.Frega A, Stentella P, De Ioris A, Piazze JJ, Fambrini M, Marchionni M, et al. Young women, cervical intraepithelial neoplasia and human papillomavirus: risk factors for persistence and recurrence. Cancer Lett. 2003;196(2):127-34.

12. Ho GY, Studentsov Y, Hall CB, Bierman R, Beardsley L, Lempa M, et al. Risk factors for subsequent cervicovaginal human papillomavirus (HPV) infection and the protective role of antibodies to HPV-16 viruslike particles. J Infect Dis. 2002;186(6):737-42.

13. Shapiro S, Rosenberg L, Hoffman M, Kelly JP, Cooper DD, Carrara H, et al. Risk of invasive cancer of the cervix in relation to the use of injectable progestogen contraceptives and combined estrogen/ progestogen oral contraceptives (South Africa). Cancer Causes Control. 2003;14(5):485-95.

14. Giuliano AR, Sedjo RL, Roe DJ, Harris R, Baldwi S, Papenfuss MR, et al. Clearence of oncogenic human papillomavirus (HPV) infection: effect of smoking (United States). Cancer Causes Control. 2002;13(9):839-46.

15. Yokoyama M, Iwasaka T, Nagata C, Nozawa S, Sekiya S, Hirai Y, et al. Prognostic factors associated with the clinical outcome of cervical intraepithelial neoplasia: a cohort study in Japan. Cancer Lett. 2003;192(2):171-9.

16. Rabelo-Santos SH, Zeferino L, Villa LL, Sobrinho JP, Amaral RG, Magalhães AV. Human papillomavirus prevalence among women with cervical intraepithelial neoplasia III and invasive cervical cancer from Goiania, Brazil. Mem Inst Oswaldo Cruz. 2003;98(2):181-4.

17. Camara GN, Cerqueira DM, Oliveira AP, Silva EO, Carvalho LG, Martins CR. Prevalence of human papillomavirus types in women with pre-neoplastic and neoplastic cervical lesions in the Federal District of Brazil. Mem Inst Oswaldo Cruz. 2003;98(7):879-83.

18. Wright TC Jr, Schiffman M, Solomon D, Cox JT, Garcia F, Goldie S, et al. Interim guidance for the use of human papillomavirus DNA testing as an adjunct to cervical cytology for screening. Obstet Gynecol. 2004;103(2):304-9.

19. Chang DY, Chen RJ, Lee SC, Huang SC. Prevalence of single and multiple infection with human papillomavirus in various grades of cervical neoplasia. J Med Microbiol. 1995;46(1):54-60.

20. Ho GY, Studentsov YY, Bierman R, Burk RD. Natural history of human papillomavirus type 16 virus-like particle antibodies in young women. Cancer Epidemiol Biomarkers Prev. 2004;13(1):110-6.

21.Schiffman M, Herrero R, Desalle R, Hildesheim A, Wacholder S, Rodriguez AC, et al. The carcinogenicity of human papillomavirus types reflects viral evolution. Virology. 2005;337(1):76-84.

22. Harper DM, Longacre MR, Noll WW, Belloni DR, Cole BF. Factors affecting the detection rate of human papillomavirus. Ann Fam Med. 2003;1(4):221-7.

23. Cuschieri KS, Cubie HA. The role of human papillomavirus testing in cervical screening. J Clin Virol. 2005;32 Suppl 1:S34-42.

24. Derchain SFM, Longatto Filho A, Syrjanen KJ. Neoplasia intra-epitelial cervical: diagnóstico e tratamento. Rev Bras Ginecol Obstet. 2005;27(7):425-33. 